\title{
Comparative study of photovoltaic self-consumption alternatives considering the Spanish legal framework
}

\author{
S. de la Torre ${ }^{1}$ and J. Á. Lagos ${ }^{2}$ \\ ${ }^{1}$ Departamento de Ingeniería Eléctrica, Universidad de Málaga, Ampliación del Campus de Teatinos, storre@uma.es \\ ${ }^{2}$ Departamento de Innovación, Iberdrola S.A., jangel.lagosc@ gmail.com
}

\begin{abstract}
This work presents a comparative study focusing on the alternatives that a small photovoltaic self-generating group of consumers face within the new legal framework in Spain. Several alternatives are presented, simulated and discussed for a representative photovoltaic generating plant serving a group of consumers that could be associated. Conclusions are duly drawn, showing which options are most favourable for the consumers. Also, a brief description of the most important features of the new legislation is presented.
\end{abstract}

Key words. Photovoltaic, Self-Consumption, Shared Self-Consumption, Legal Framework, Tariffs.

\section{Introduction}

Since April 2019, there has been a new legal framework regulating self-consumption in Spain, which opens the door to several scenarios that could be interesting and that have not yet been put into practice, including collective self-consumption. This is where the innovative nature of our analysis lies, as it studies scenarios that are permitted by law but are not yet being widely implemented. Also, collective self-consumption can have a great impact on the energy sector, given that most Spaniards, according to Eurostat [1], live in residential buildings. This topic was initially studied from a different perspective by other authors $[2,3]$

\section{Spanish Legal Framework around Self- Consumption}

The Spanish Electric Sector is regulated by a number of Laws and Royal Decrees that establish many details regarding its operation, its financing and many other aspects of the normal functioning of the industry. The main Law in place to regulate the electric industry is Law 24/2013 [4]; this is a general law regarding the electric sector as a whole. More specific legislation is also in place to regulate self-consumption (SC) and photovoltaic generation; of particular interest for this work are the following:

- Royal Decree-Law 15/2018, urgent measures for energy transition and consumers protection [5].

- Royal Decree 244/2019, regulating administrative, technical and economic conditions for electric energy self-consumption [6].

Royal Decree-Law 15/2018 [5] is divided in 3 main parts, dealing with consumer protection, electric energy self-consumption and energy transition. Specifically, the second section is the most relevant for our study; in that section several relevant rules are presented eliminating limitations for SC development in the country, also a set of simplifications on bureaucracy is set in place regarding new SC plants; also relevant is the legalization of "collective self-consumption", which allows for shared SC facilities, thus facilitating the installation of new systems. Royal Decree 244/2019 [6] deals with many implementation details related to Roya Decree-Law $15 / 2018$; in particular, some important concepts are defined, as SC plants without excess energy, SC plants with excess energy, as well as compensation of surpluses; also a distinction is made between SC plants using an interior network and SC plants using the distribution network. Finally, this piece of legislation establishes a system similar to "net-billing" for the excess energy produced by SC generators.

\section{Case study for comparisons}

In the present section data will be provided regarding the case study that has been analysed in detail in order to consider all the options available to a Spanish SC producer within the new legal framework.

\section{A. Household, consumption and radiation data.}

First of all, given the Spanish structure of homes and housing, an apartment building type of housing is selected both because it is a very frequent form of housing for Spanish families and also because the concentration of people on a single building provides an incentive for the installation of shared SC facilities [7]. In particular, a building comprising a street-level common area and 4 additional floors, with 4 households, each is considered. In order to estimate the energy consumption in this building some new assumptions are needed. For the inhabitants in each of the households we also have studied the data presented in [7]. In light of this data, we have assumed the following configuration for the building, which is representative of average Spanish houses: out of the 16 households in the building, 9 are assumed to be a family comprising a couple and 2 children (Type A), while the remaining 7 households are inhabited by a couple without children (Type B). In this way, with only 2 different types of households we obtain a good representation of the Spanish average house composition. In order to compute the amount of energy consumed by all the households in the building, some 
additional assumptions must be made; to that end we have used data from [8]. This source provides estimates for daily energy consumption of different household compositions; moreover, three different sets of energy consumption data are provided for each household composition in order to take into account the difference in weather over a year. The three energy consumption profiles represent summer, winter and spring-fall, respectively; energy demand data is show on Fig. 1, for each of them.
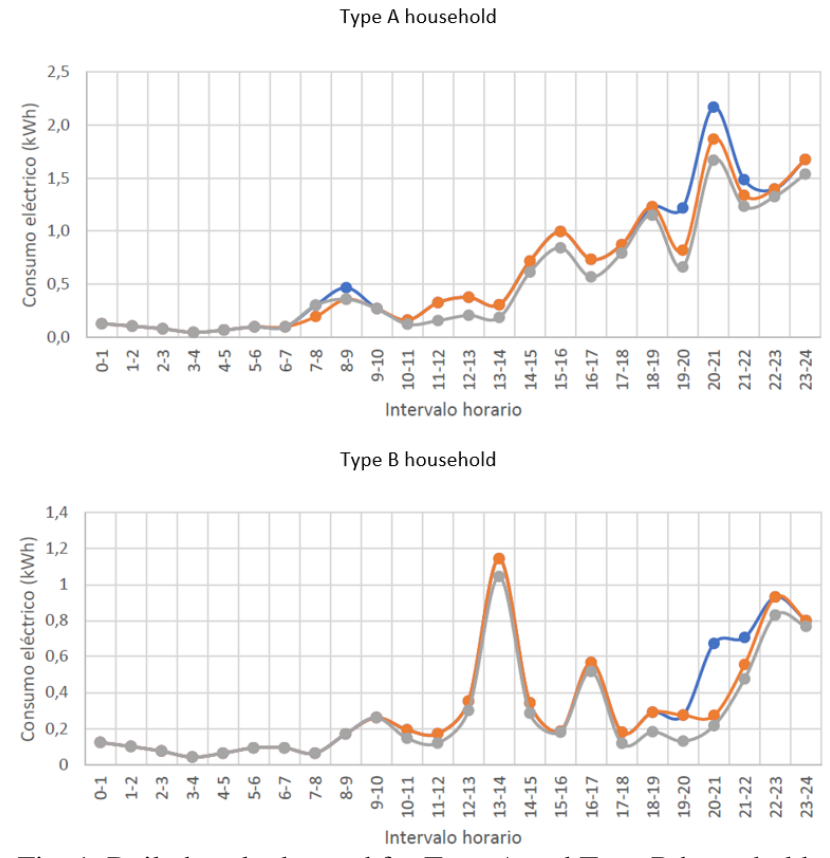

Fig. 1. Daily hourly demand for Type A and Type B households, for three different patterns (winter - blue lines; summer - grey lines; fall and spring - orange lines)

A real location is needed for our simulations; we have selected the city of Madrid, both because it is the most populated town in the country and also because its climate can be considered representative of the country as a whole, to some extent. Radiation data for every location is readily available, we have used [9].

\section{B. PV plant design}

First one must select the orientation of the PV panels; considering all the data available, we have selected a value of $10^{\circ}$ west for the azimuth and $35^{\circ}$ for the tilt angle, which are common values. Next, we must select the peak power for the PV plant; aiming at satisfying $80 \%$ of daytime demand with the PV system, we have selected a value of $29,08 \mathrm{~kW}_{\mathrm{P}}$ as our nominal power. For the solar panels we have selected a model with $21 \%$ average efficiency and $345 \mathrm{~W}$ of nominal power. With this numbers in mind we will need around 84 panels for our PV plant, however, we found that 88 is the optimal number after some iterations. For the inverter we select a commercially available model with nominal power of $27,6 \mathrm{~kW}$. In order to connect the panel to the inverter we select a configuration with 8 chains, each of which contains 11 panels connected in series. Note that the total capturing surface is around 143 $\mathrm{m}^{2}$, however, the PV plant will use some $450 \mathrm{~m}^{2}$ of roof surface.
It is important to take into account that for some of the alternatives considered later in the case studies an energy storage system is needed. To that end, we have implemented 2 different values for the size of the energy storage system: i) a "Big storage system" and ii) a "Small storage system"; the next section provides the numeric values.

Using the adequate software, we can calculate accurately the amount of energy generated by our system for each day of the year. The total yearly energy generation for our system is estimated at around 53.000 $\mathrm{kWh}$. For example, Fig 2 shows the amount of energy generated during one day in the month of May.

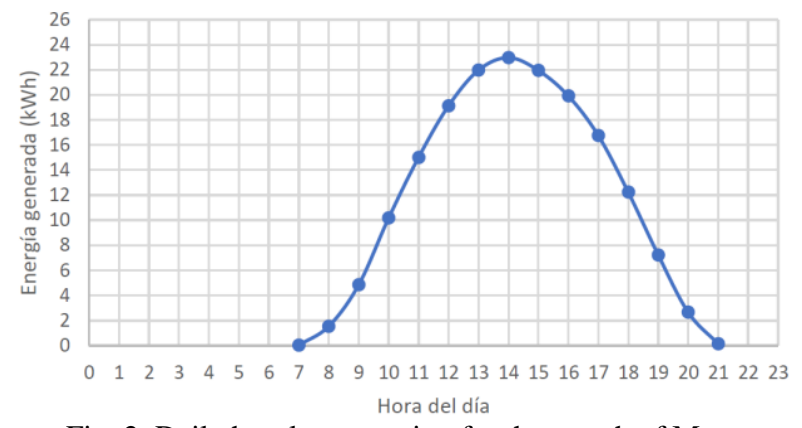

Fig. 2. Daily hourly generation for the month of May.

\section{Energy balance for each household}

First of all, we assume that all the households in the building will participate equally in the shared self-consumption scheme, and hence we assign each of them a participation factor equal to $1 / 16$. Now we need to compute for each household type, for each month and for each hour of the day an energy balance. This energy balance tries to establish how the demand is satisfied at every hour for each house, considering the following parameters:

- PDem: House demand. It is a value known in advance, it represents the energy needs of the house.

- PGen: Proportion of the power generated by the PV system that each house is allowed to use.

- PNet: Power consumed from the external network, produced by a generic power utility. This value will only be greater than zero if PDem > PGen.

- PEx: Excess power, this is the amount of energy that the house could consume from the PV system but does not needed. This value will only be greater than zero if PDem < PGen. In some scenarios, this energy could be sold back to the network for some profit or stored in a shared storage system.

These magnitudes are illustrated in Fig 3.

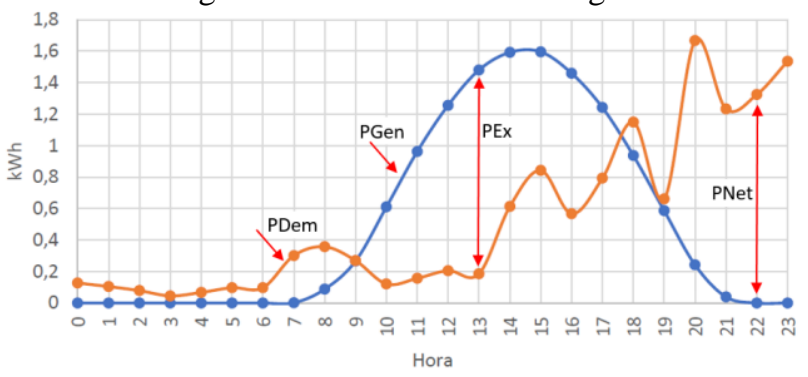

Fig. 3. Daily hourly generation and demand for one specific Type A house for the month of July. 
Once all these computations are performed, we have data regarding the energy balance for each hour of each day for each type of household. As an example, Table I shows the results for a Type A house in the month of July:

Table I. - Energy balance for Type A house in July.

\begin{tabular}{|c|c|}
\hline Concept & Amount \\
\hline Total demand & $390,7 \mathrm{kWh}$ \\
\hline Total consumption from the network & $215,8 \mathrm{kWh}$ \\
& $(55,2 \%)$ \\
\hline Total consumption from PV system & $175,0 \mathrm{kWh}$ \\
& $(44,8 \%)$ \\
\hline Total excess energy & $208,2 \mathrm{kWh}$ \\
\hline
\end{tabular}

It is clear that a big amount of energy is consumed from the PV system; also it is clear that there is a large amount of excess energy, as no storage system is considered up to this point.

\section{Comparison of the different available alternatives}

According to Royal Decree 244/2019 [6], there are 3 main ways in which this building can get connected to the network, the differences are related to the treatment of excess energy both in terms of energy flow and in terms of compensation. These options are:

- CASE 1: Shared self-consumption with Excess energy and with a compensation mechanism.

- CASE 2: Shared self-consumption with Excess energy and without compensation mechanism.

- CASE 3: Shared self-consumption without Excess energy and with a compensation mechanism.

In order to provide a more thorough analysis, some additional alternatives are considered in our study. First of all, for each case, we consider the option of including an energy storage system (battery) or not. Additionally, we can consider either a general tariff $(\mathrm{G})$ or a special "time discrimination" tariff (TD). Also, we must consider both types of households previously described. All in all, we have a total of 32 different scenarios to simulate. For comparative purposes we also present energy cost data for the case where no PV plant is installed. Total annual cost, including all applicable costs and taxes in Spain at the time of writing are presented in the following.

\section{A. Energy cost without PV system}

This is a relatively simple case for which all the households in our building are consuming energy but there is no available PV system to provide SC. In this case, the results are:

Table II. - Total annual cost without PV System.

\begin{tabular}{|c|c|}
\hline Household & Cost \\
\hline Type A - TD tariff & $969,35 €$ \\
\hline Type A - G tariff & $978,48 €$ \\
\hline Type B - TD tariff & $600,74 €$ \\
\hline Type B - G tariff & $624,89 €$ \\
\hline
\end{tabular}

\section{B. Energy cost with PV system: CASE 1}

In this case, the excess energy generated by the PV system that is not needed in each household can be sold to the electric company at a certain price that is fixed by the legislation; the calculation of this price is convoluted, but, as an approximation, it can be estimated as a $45 \%$ of the energy price when buying from the network. The electric company is obliged to buy this energy.

As previously mentioned, cases with energy storage systems are also included in our simulations; in order to reasonably size the storage system for the building, the needs of each household are considered, assuming that trying to store all the excess energy will be uneconomical, after some calculations a reasonable number of $24.3 \mathrm{kWh}$ is selected as ideal for the small storage size. Table III contains the main results obtained from the simulations of CASE 1 .

Table III. - Total annual cost for all scenarios in CASE 1.

\begin{tabular}{|c|c|}
\hline CASE 1 scenarios & Total Annual Cost \\
\hline Type A - TD tariff - No Storage & $586,13 €$ \\
\hline Type A - TD tariff - With Storage & $527,25 €$ \\
\hline Type A - G tariff - No Storage & $613,47 €$ \\
\hline Type A - G tariff - With Storage & $568,54 €$ \\
\hline Type B - TD tariff - No Storage & $292,20 €$ \\
\hline Type B - TD tariff - With Storage & $266,89 €$ \\
\hline Type B - G tariff - No Storage & $316,58 €$ \\
\hline Type B - G tariff - With Storage & $289,41 €$ \\
\hline
\end{tabular}

Note that in all cases, the cost is smaller for systems with a TD tariff; also, note that cost is smaller for houses when a storage system is included.

\section{Energy cost with PV system: CASE 2}

This case is similar to the previous one, but the excess energy generated by the PV system is not sold to the electric company, it is sold in the spot market; the main advantage is that the selling price can be higher and that there are no limits on the sale of surplus electricity to the grid; whereas in CASE 1 the amount of energy that can be compensated is capped; the main disadvantage is that the process to sell the energy is more complicated and an intermediary is needed to operate these transactions. The selling price will depend on market conditions, but for the present work it will be estimated as around a $50 \%$ of the energy price when buying from the network. Table IV contains the main results obtained from the simulations of CASE 2.

Table IV. - Total annual cost for all scenarios in CASE 2.

\begin{tabular}{|c|c|}
\hline CASE 2 scenarios & Total Annual Cost \\
\hline Type A - TD tariff - No Storage & $597,71 €$ \\
\hline Type A - TD tariff - With Storage & $535,01 €$ \\
\hline Type A - G tariff - No Storage & $625,04 €$ \\
\hline Type A - G tariff - With Storage & $576,31 €$ \\
\hline Type B - TD tariff - No Storage & $286,90 €$ \\
\hline Type B - TD tariff - With Storage & $227,65 €$ \\
\hline Type B - G tariff - No Storage & $318,88 €$ \\
\hline Type B - G tariff - With Storage & $270,15 €$ \\
\hline
\end{tabular}

\section{Energy cost with PV system: CASE 3}

In this case the excess energy cannot be sold neither to the electric company nor to the spot market, however, compensation among the households sharing the PV plant is allowed and money is exchanged among the different households whenever this happens. The prices for these exchanges are, for the household with energy surplus, the same price fixed by law as in CASE 1, while 
for the household that receives the energy surplus, it pays the same price as it would pay if this energy was coming from the grid. Note that under the conditions of CASE 3 there is a lot of excess energy that can't be used in any way, because very often when one household has an excess of energy from the PV system, the rest of the houses in the building will not need it, so this energy could be lost entirely; this situation provides a great incentive for the use of storage systems, as it becomes a very efficient way of making the system economical, by allowing for the consumption of all the generated energy. To that end, we have studied the problem with two different storage systems, the "Small" system is identical to the one used for CASE 1 and $2(24,3 \mathrm{kWh})$; and the "Big" system is more than 3 times larger: $80,9 \mathrm{kWh}$. All the results are presented in Table V.

Table V. - Total annual cost for all scenarios in CASE 3.

\begin{tabular}{|c|c|}
\hline CASE 3 scenarios & Total Annual Cost \\
\hline Type A - TD tariff - No Storage & $687,71 €$ \\
\hline Type A - TD tariff - Small Storage & $595,36 €$ \\
\hline Type A - TD tariff - Big Storage & $474,13 €$ \\
\hline Type A - G tariff - No Storage & $715,04 €$ \\
\hline Type A - G tariff - Small Storage & $636,65 €$ \\
\hline Type A - G tariff - Big Storage & $477,98 €$ \\
\hline Type B - TD tariff - No Storage & $397,90 €$ \\
\hline Type B - TD tariff - Small Storage & $309,00 €$ \\
\hline Type B - TD tariff - Big Storage & $258,71 €$ \\
\hline Type B - G tariff - No Storage & $429,88 €$ \\
\hline Type B - G tariff - Small Storage & $351,49 €$ \\
\hline Type B - G tariff - Big Storage & $265,48 €$ \\
\hline
\end{tabular}

\section{E. System financing and investment return}

In terms of expenses, a cost of $€ 1.5 / \mathrm{Wp}$ is considered for CAPEX, which includes equipment, studies and engineering, with a separate price of $€ 800 / \mathrm{kWh}$ for batteries. For OPEX, a value of $2 \%$ of the total CAPEX is considered, taking into account an inverter replacement after 15 years, and in the scenarios that contemplate battery replacement, these are changed after 13 years. Similarly, for decommissioning costs, $5 \%$ of the CAPEX is used at the end of the 25 years of the project lifetime. Besides, the profitability studies are carried out taking into account that the residents contribute $5 \%$ of the most basic initial investment (that which does not include batteries). Thus, for the remaining amount to be contributed, a loan is requested. For all loans, an annual repayment periodicity and an average APR of $8 \%$ according to the Bank of Spain [10] is taken into consideration. Thus, in all scenarios, a loan repayment term of 10 years is considered. For "small" storage, a term of 15 years is also analyzed, and for "big" storage, a term of 20 years, to obtain more reasonable annual instalments. As for inflation, an average historical value of $1.96 \%$ is taken for the variation of the general CPI, while this value is $2.77 \%$ for the electricity CPI.

To calculate the profitability, NPV is used to update the cash flows to the present and to obtain the year of payback of the investment; the results are shown in Table VI.
Table VI. - Studied scenarios in the economic analysis.

\begin{tabular}{|c|c|c|c|c|}
\hline \multicolumn{3}{|c|}{ Scenario } & \multirow[t]{2}{*}{ NPV } & \multirow{2}{*}{$\begin{array}{l}\text { Investment } \\
\text { return }\end{array}$} \\
\hline Case & $\begin{array}{l}\text { Battery } \\
\text { replacement }\end{array}$ & $\begin{array}{c}\text { Loan } \\
\text { repayment }\end{array}$ & & \\
\hline Case 1 & - & 10 years & $51.602 €$ & 13 years \\
\hline \multirow{4}{*}{$\begin{array}{c}\text { Case } 2 \\
\text { ("Small" } \\
\text { storage) }\end{array}$} & \multirow{2}{*}{ No } & 10 years & $34.6289 €$ & 18 years \\
\hline & & 15 years & $26.807 €$ & 20 years \\
\hline & \multirow{2}{*}{ Yes } & 10 years & $19.430 €$ & 21 years \\
\hline & & 15 years & $11.6089 €$ & 23 years \\
\hline \multirow{4}{*}{$\begin{array}{l}\text { Case } 3 \\
\text { (“Big" } \\
\text { storage) }\end{array}$} & \multirow{2}{*}{ No } & 10 years & $-47.443 €$ & - \\
\hline & & 20 years & $-75.174 €$ & - \\
\hline & \multirow{2}{*}{ Yes } & 10 years & $-98.106 €$ & - \\
\hline & & 20 years & $-125.837 €$ & - \\
\hline
\end{tabular}

Note that for the cases with batteries, the scenarios have been studied with and without the replacement of these, and for different loan repayment terms.

It can be seen that no self-consumption scenario with "Big" storage batteries is profitable. This conclusion can be extended to all the scenarios not included in the table but that use "Big" storage systems; it is clear because, in the case analyzed, almost all of the surpluses are stored.

For the scenarios with "Small" storage batteries, the investment turns out to be profitable but not sufficiently attractive, since it is recovered very late even assuming a lifetime of 25 years for the installation. These results would be similar for the combination of "Small" storage and Case 1, since the savings of this configuration are approximately the same as those studied in the present case.

It turns out that Case 1, which does not use batteries, is the most profitable case analyzed, recovering the initial investment in year 13 .

Therefore, after the economic study carried out, the most interesting options are those that do not use batteries and receive remuneration for the surpluses.

\section{Final conclusions}

As for the new legislative framework in Spain, it has introduced new features, such as collective selfconsumption or the compensation of surpluses in the same electricity bill, and has eliminated power limitations, the back-up toll, and simplified procedures.

After having carried out a thorough analysis in which it has been determined which is the typical case in terms of number of floors of the residential building, number of dwellings in said building, size of each dwelling, most typical composition of Spanish households and consumption for each type of household, and after having sized the fundamental components of the selfconsumption installation, it is concluded that collective self-consumption in a typical residential building in Spain is profitable, recovering the investment in a reasonable period of time taking into account the useful lifetime of said installation.

Although it is true that the greatest savings in billing take place in scenarios in which batteries are used, in these scenarios the investment is not interesting or even profitable depending on the storage capacity considered. Therefore, the best balance between annual savings, 
return on investment and payback years, is found in those scenarios in which the surpluses discharged to the grid are compensated, as long as a battery system is not used. The savings are very similar in cases 1 and 2, although in this latter case the savings are slightly higher.

Thus, the collective self-consumption studied is more interesting the more similar the demand curve and the generation curve are, since the price received for the surplus low compared to the price charged for consumption from the grid. In addition, tariffs with hourly discrimination (Spanish tariff 2.0 DHA) are more economically attractive than general tariffs (Spanish tariff $2.0 \mathrm{~A})$.

The analysis has been carried out without taking into account any type of regional subsidy or any type of tax incentive at the municipal level, so that these installations are profitable on their own without the need to be subsidized in any way, as long as a setting is chosen in which surpluses are remunerated and energy storage systems are not installed.

Finally, the current legislative framework indeed has very positive aspects, such as collective self-consumption, it also has some negative aspects, such as limiting the simplified compensation mechanism to a maximum of one month. However, the fact that Spain now has legislation that encourages self-consumption without premiums or subsidies, thus allowing its economically sustainable development can be considered an important advancement for the energy sector.

\section{References}

[1] Eurostat, «Housing statistics» May. 2020. [on-line]. Available at: https://ec.europa.eu/eurostat/statistics-

explained/index.php/Housing_statistics\#Type_of_dwelling

[2] J. López Prol, K. W. Steininger, "Photovoltaic selfconsumption is now profitable in Spain: Effects of the new regulation on prosumers' internal rate of return", Energy Policy, Elsevier, November 2020.

[3] N. Moussa, P. Arboleya, J. Izquierdo, "Study of a Shared Self-Consumption System Applied to Neighborhood Communities in Urban Environments", Master Thesis. [on-line] Available at: https://digibuo.uniovi.es/dspace/bitstream/handle/ 10651/52608/TFM_NourMoussa.pdf

[4] Law 24/2013, September $26^{\text {th }} 2013$ for the Spanish Electric Sector. Boletín Oficial del Estado. www.boe.es

[5] Royal Decree-Law 15/2018, October $5^{\text {th }} 2018$, urgent measures for energy transition and consumers protection. Boletín Oficial del Estado. www.boe.es

[6] Royal Decree 244/2019, April $5^{\text {th }} 2019$, regulating administrative, technical and economic conditions for electric energy self-consumption. Boletín Oficial del Estado. www.boe.es [7] Instituto Nacional de Estadística "Censos de Población y Viviendas" 2011. [on-line]. Available at:

https://www.ine.es/censos2011/tablas/Informe.do

[8] Í. Les Aguerrea, C. Azacárate and F. Mallor "Modelo de simulación del consumo de energía eléctrica doméstica" Universidad Pública de Navarra, Pamplona, [on-line]. Available at: https://hdl.handle.net/2454/16924

[9] The European Commission's science and knowledge service, "Photovoltaic Geographical Information System (PVGIS)" [online]. Available at:

https://re.jrc.ec.europa.eu/pvg_tools/es/\#MR

[10] Banco de España, «Tabla de tipos de interés, activos y pasivos, aplicados por las entidades» 2020. [on-line]. Available at: productosservici/relacionados/tiposinteres/guia-textual/ tiposinteresprac/Tabla_de_tipos_a0b053c69a40f51.html 